\title{
Extension of Library Services in Colleges and Universities under the "Double Creation" Fever
}

\author{
Li Zhu' ${ }^{1}$, Fangfang Wu ${ }^{1}$, Yi Han ${ }^{1}$ \\ ${ }^{1}$ Sichuan Technology and Business University Library, China
}

Keywords: mass entrepreneurship; mass innovation; library service extension

\begin{abstract}
With the vigorous development of "double creation" activities, the service objects and service content of the library in colleges and universities are also changing, and the demand for users presents a trend of diversification, individuation and specialization. The library in colleges and universities must expand and extend the service space, take employment, creation and innovation as the theme and build a good platform for the theme. It is necessary to create a good atmosphere for innovation, provide policy interpretation and meticulous service for contemporary college students, and give full play to their functions as a booster for social economic and cultural development. Extending service is the embodiment of the function of the public library. Based on the background of "double creation", this paper expounds the opportunities and challenges of the public library in modern service, and gives some suggestions on relevant solutions. At the same time, it also puts forward some new ideas that the extension of the service of the library in colleges and universities should be in line with the National Library.
\end{abstract}

\section{Introduction}

With the development of the society, the requirements of the library are different in different times. The extension of library service and the popularization of reading under the background of "double creation" are the requirements for the library at the present stage of our country. The joint participation of multiple subjects is the necessity of the development of the library, and the extension of service is an important measure for the library to play the advantage resources and construct the public cultural service system; reading and popularization is an important way of maximizing the utilization efficiency of the library.

\section{The Significance and Challenge of Library Service Extension under the Background of "Double Creation"}

University Library Service Extension and reading promotion are the efforts made by the library to improve the quality of service to readers. On the one hand, it expands the service scope of the library, extends the service from the service field, the service crowd, and then to the service content. On the other hand, it has made various forms of popularization for the readers' most basic rights and interests - reading, which has enhanced the students' interest in reading and deepened the readers to the library. Understanding.

\subsection{The significance of library service extension.}

Library service extension. With regard to the extension service of the library, Chinese scholars have given different definitions. Wu Hanhua believes that library services are divided into basic services and extended services. Extension services are based on the realization of basic knowledge services, and use of the library's literature, librarians, equipment, houses, brand influence and other advantages. The reader provides an extension service. In short, extended services are extensions or extended services that libraries develop on the basis of regular services. The breadth and depth of library services have been extended. 
Library reading promotion. Library reading and popularization is the extension of Library's knowledge resources and reading methods, because the value of library literature resources is not the collection, but the utilization efficiency and the circulation rate. Reading promotion can better help readers understand the library's collection of documents, and make rational and effective use of library resources.

Since the development of the library has been devoted to providing better services for the readers, the breadth and depth of the content of library service extension and reading promotion shows the efforts made by the library on all levels, fields, and time, which are as much as possible.

\subsection{The challenge of library service extension under the background of "double creation".}

Although some libraries in our country have made good achievements in the extension of library service and the promotion of reading, more libraries are in a steady state. They can not conform to the trend of the times and keep up with the footsteps of the society. It has caused the present situation of some libraries which are far from the need of the social library. Please. Therefore, the general library should adhere to the basic concept of "people-oriented", actively seek the direction of the development of the library, formulate a reasonable and standardized activity plan, take some practical and practical action, so that the library will be revitalized in the new period. Under the background of "double creation", the challenges faced by university libraries are as follows:

\section{Exploration of Library Service Extension under the Background of "Double Creation"}

\subsection{Sound laws and regulations.}

There are some regulations on Libraries in China, such as the library work regulations and the regulations of the Beijing library, most of which do not have the statute of complete legal effect. A good library law can indicate the direction of the library cause, and let the management, construction and reader service of the library be dealt with. It is more scientific and more scientific. Therefore, improving laws and regulations is an essential requirement for the development of library cause.

\subsection{Publicity increasing.}

Social participation is not enough, on the one hand is not comprehensive understanding of the library, on the other hand, library propaganda is not enough. The library should be good at making use of all kinds of advanced technology, looking for new propaganda platform in this era of information network, using new media to carry out propaganda, such as setting up website, opening blog, paying attention to micro-blog and so on, so that society can better understand the library. Social groups, organizations or individuals can also actively participate in library construction through some ways and means to help libraries carry out activities.

\section{Library Service Extension in Various Provinces and Cities}

In recent years, in order to create a cultural reading atmosphere for the whole society in the whole society, we advocate the public to use many kinds of carriers, read more books and read good books. Libraries in all parts of the country actively expand service fields, broaden service channels, innovate service means, extend service positions, and carry out various forms of mobile extension services. To build the central library with provincial and provincial libraries, to the surrounding University City and county library, children's branch library, community mobile library radiation pattern, 24 hour block self-help library, mobile book car, electronic book down-loader and public electronic reading room as a supplement, "Sun book bar" as the brand, the digital library for virtual service The public library service network covering the whole city and serving the whole people.

\subsection{Community mobile library and children's branch.}

Based on the reality of this library, the libraries of various provinces and cities break through the service mode that the traditional library is limited to in the library. In line with the purpose of "the 
convenience of the reader and the service community", the service function and the scope of service are continuously strengthened and the community mobile Libraries (stations) and children's branches have been first established in the region, and their services are extended to the area. Communities and schools, carrying out mobile services, regular distribution of books, and on the basis of outside reading work, actively carry out rich and colorful reader activities, publicize the library, and expand the social impact of the library. Initially, the public cultural service system of the surrounding counties and districts was formed by taking provincial and municipal libraries as the center.

\subsection{Sunshine book bar.}

The "Sunshine book bar" is the main body of promoting the cultural taste of the city and creating a national reading atmosphere. It is one of the cultural leisure places in which many municipal libraries are open to the public for free public welfare. "Sunshine book bar" is an amazing-functional leisure space which integrates library, coffee leisure and book friend salon. It is a fashion culture and leisure place integrating "Book Culture" and "bar culture". "Sunshine book bar" not only provides a reading and rest place for the public, but also serves as a platform for cultural exchanges among the citizens.

\section{Library in Colleges and Universities Helps College Students for "Double Creation"}

Innovation is the soul of a nation and an inexhaustible motive force for the prosperity of a country. It is of great significance to improve the creative ability of college students. It is the primary condition to inherit the achievements of China's advanced knowledge and the inexhaustible motive force to create new discoveries and catch up with the advanced productive forces of the world. Only with the continuous development of the spirit of innovation can the national cause be carried out smoothly. Therefore, it is of great historical significance for college students to actively think and take the initiative to participate in the innovation activities.

\subsection{Create an active innovation atmosphere for colleges and universities.}

The creation of innovative atmosphere can provide environmental support for innovative behavior. Active and enthusiastic innovation scenes can create innovative consciousness and inspiration for college students themselves. As an excellent environmental resource for college students to cultivate innovative thinking consciousness, the university library should keep up with the needs of the development of the times, use strict standards for themselves, carefully study the advanced service concept and development model of local libraries in various provinces and cities, and actively create a good innovative study atmosphere for College students. In order to improve and improve the existing service of the university library, we should strive to improve and improve the existing service of the university library. The promotion of linkage innovation projects is not only the embodiment of the functions of university libraries, but also the extension of functions. In order to carry out the innovation project, the extension service of the University Library and the "double creation" promote each other and create a good innovation atmosphere for the contemporary college students.

\subsection{Provide realistic platform for undergraduates to accumulate basic knowledge continuously.}

It is certain that good basic knowledge is a good basis for the birth of innovative achievements. Excellent innovative achievements are full of technological content. Without solid knowledge accumulation and deep knowledge, it is impossible to breed good inventions. During college, college students must learn basic knowledge, including the use of mathematics, English, computer and Internet, and basic courses required by the major. The reason is that most of the innovation results come from the deep combination of basic knowledge. In addition, it is difficult for college students to understand the advanced application technology without a good foundation. Therefore, laying a solid foundation for basic knowledge plays a vital role in the study of new discoveries. However, we must not give up the foundation of the basic knowledge and give up the extension of the basic knowledge and the discovery of the new knowledge because of the learning of basic knowledge. Otherwise, we can get into the quagmire of one-sided theory. Therefore, we need to improve our practical and practical abilities while studying specialized courses. 
The improvement of College Students' self innovation ability is a task with a long and long way to go, but it plays an important role in improving our independent innovation ability, revitalizing national science and technology and developing national economy. It is also an inevitable requirement for improving the comprehensive quality of college students and taking the responsibility of building a harmonious society in China. As the largest information base for college students to accept knowledge, the university library should make great efforts to students actively become an important role of innovation activities and make their own contribution to the successful implementation of the independent innovation.

\section{Conclusion and Prospect}

We should deepen the reform of the science and technology system, promote the reform of the price system, expand the pilot reform of the free trade area, deepen the rural reform, and promote the development of private banks. Since this year, our country has persisted in taking major issues as the guidance, and has made new and great stride in the comprehensive deepening of the reform. Many years of gnawing "hard bones" have made breakthrough progress and achieved stage results, adding oil to the mass entrepreneurship and innovation, and added strength to steady growth, employment and efficiency. This year's reform and deployment around double innovation have been pragmatic and effective. We have truly adhered to the problem oriented, realistic problems, practical prescription and practical measures. For example, in the development of public space, it puts forward the characteristics of the centralized office of new incubators such as public creation, and encourages the combination of reality to simplify the formalities of residence registration, and take measures such as one-stop window, online declaration and license joint operation to provide convenience for the business registration of entrepreneurial enterprises; and deepen the innovation and entrepreneurship education in Colleges and universities. In the reform, we put forward the implementation of the flexible school system, the relaxation of the students' fixed number of years of practice, the adjustment of the academic process, the retention of the school records and the innovation of the business. Reform of the registration system of domicile, such as group registration.

Different organizations and individuals should find their own reasonable positioning in innovation and entrepreneurship, and do not drift with the tide and parrot. University double creation education is more specific. Education is the process of making man a man, the growth course of life, and will never be out of fashion. As a brand new form of education, double creation education will not only die out in the future, but also the development trend of it. How should colleges and universities win the rapid development of dual education in the universality and particularity? Not every university can imitate a successful double creation education mode, and most of them are crossing the river by feeling the stones. Only by understanding their own personality and characteristics can we find a more cooperative mode or communication mode that is more important to our development. Understanding the advantages and differences of dual education in various countries and regions is aimed at forming complementary advantages with their schools and promoting double creation education to a higher level. We should take the media platform as a bridge, win together hand in hand, and jointly create a community of innovative and entrepreneurial education community with the integration of development concepts, unimpeded flow of elements, communication of scientific and technological facilities, integration of innovation chain, and smooth communication of personnel. Further exchanges will form more practical measures to promote innovation and entrepreneurship education in Colleges and universities, deepen the cooperation of colleges and universities, improve the level of cooperation in running schools, promote cooperation at a higher level and greater scope, establish a long-term mechanism, bring into full play the cultural and disciplinary advantages of all schools, actively explore new mechanisms of collaborative education, and establish a new mechanism for the future, and establish a future facing the future. The community of innovation and entrepreneurship education. 


\section{References}

[1] Wang Xiujuan. Extension and expansion of the service function of university libraries for the construction of urban community culture. Journal of [J]. Agricultural Library and information science, 2018, (03).

[2] Zhang Yongan, Xi Hai Tuo. Quantitative evaluation of "mass entrepreneurship and innovation" policy - [J]. Intelligence magazine, 2018, (03), with 2017 of the 10 double invasive policy information. 